\title{
Increased wall thickness using ultrasonography is associated with inflammation in an animal model of experimental colitis
}

This article was published in the following Dove Press journal:

Clinical and Experimental Gastroenterology

26 September 2012

Number of times this article has been viewed

\section{Gülen Arslan Lied' \\ Anne Marita Milde ${ }^{2}$ \\ Kim Nylund ${ }^{1,3}$ \\ Maja Mujic' \\ Tore Grimstad ${ }^{1,4}$ \\ Trygve Hausken ${ }^{1,3}$ \\ Odd Helge Gilja ${ }^{1,3}$}

'Institute of Medicine, University of Bergen, Norway; ${ }^{2}$ Department of Biological and Medical Psychology, University of Bergen, Norway;

${ }^{3}$ National Centre for Ultrasound in Gastroenterology, Haukeland

University Hospital, Bergen, Norway;

${ }^{4}$ Division of Gastroenterology,

Stavanger University Hospital,

Stavanger, Norway
Correspondence: Gülen Arslan Lied

Division of Gastroenterology,

Department of Medicine,

Haukeland University Hospital,

Bergen N-502I, Norway

Tel +4755972130

Fax +4755974973

Email Gulen.Arslan@med.uib.no
Abstract: Experimentally induced colitis is used in animals to investigate pathophysiological mechanisms in inflammatory bowel disease. When following disease course and treatment effects, it should be possible to perform repeated measurements without harming the animals. This pilot study was performed to investigate whether transabdominal ultrasound using a clinical scanner could be used on rats to demonstrate bowel inflammation in an experimental colitis model. Colitis was induced by either 5\% dextran sodium sulfate (DSS) in drinking water for 7 days or a single dose of intracolonic trinitrobenzene sulfonic acid (TNBS). Using ultrasonography, wall thickness of distal colon, cecum, and small bowel was recorded prior to and after DSS, and prior to, 2, and 7 days after TNBS. Blood (tumor necrosis factor [TNF]-alpha) and fecal samples (HemoFEC occult blood) were taken from each group on the same days as sonography. Thereafter, rats were killed and specimens for histology were taken. Wall thickness of distal colon, not of cecum or small bowel, increased significantly after 7 days of DSS, and wall thickness of both distal colon and small bowel increased on day 2 and 7 after TNBS. TNF-alpha increased after 7 days in the latter group only. There was a significant correlation between ultrasonographic measurements and combined histology score of distal colon in the DSS group. HemoFEC was also positive in accordance with sonographic and histological features. Increased intestinal wall thickness in response to both DSS- and TNBS-induced colitis was able to be visualized by transabdominal sonography. Moreover, ultrasound findings, occult blood sampling, and histological findings supported each other, indicating that ultrasonography can be used to assess inflammation in a rat experimental model.

Keywords: transabdominal bowel sonography, inflammatory bowel disease, experimental colitis, dextran sodium sulfate, trinitrobenzene sulfonic acid

\section{Introduction}

Inflammatory bowel disease (IBD), which includes Crohn's disease and ulcerative colitis, is a chronic and relapsing-remitting inflammatory condition of the gastrointestinal tract. It afflicts mostly young people, and represents an important public health problem affecting both patients' education, working abilities, social life, and quality of life. The etiology is still unknown, but is most likely an interaction of genetic, immune, and environmental factors with continuous immune-mediated inflammation. ${ }^{1}$ The latest research in this area has stimulated the discovery of novel therapeutics for IBD.

Experimental colitis models are used in animals to investigate the different factors in IBD by inducing acute or chronic intestinal inflammation. These models include administering chemicals such as acetic acids, formalin, indomethacin, dextran sodium sulphate (DSS), trinitrobenzene sulfonic acid (TNBS) in ethanol, carrageenan, or immune 
complexes to rodents. ${ }^{2}$ All these substances have their own pros and cons. During the last decade, DSS, which is given as a replacement for normal drinking water, has been preferred over other substances due to its noninvasive administration, wherein the animals quickly develop colitis and anesthesia is not required. The TNBS model is characterized by a simple process (single dose of intracolonic administration), reproducible colonic damage, and inexpensive and short duration of the experiment, but the animals are exposed to anesthesia during the administration. ${ }^{3-5}$ TNBS also induces more widespread transmural inflammation different from DSS-induced colitis. Hence, the models closely mimic the clinical and morphological features of human Crohn's disease and ulcerative colitis, respectively.

Transabdominal bowel ultrasound is an established imaging procedure in patients with IBD. ${ }^{8,9}$ It is used for investigating the degree of colonic inflammation, its relation to patient symptoms and for follow-up. ${ }^{10}$ Typical ultrasonographic findings in IBD patients are increased wall thickness, infiltrations, ulcerations, flow alterations, changes in stratification, and complications such as abscesses, stenosis, and fistulas. ${ }^{11-13}$ A detailed image of the bowel including the separate wall layers can be obtained using a 7.5-14-MHz linear transducer.

In experimental studies, a variety of optical and nonoptical imaging techniques, including colonoscopy, chromoendoscopy, optical coherence tomography, microcomputed tomography, ultrasound elasticity imaging, and magnetic resonance imaging alone or combined with positron emission tomography have been used to provide anatomical and functional information about the colon. ${ }^{14-16}$ However, each of the techniques has some disadvantages and limitations.

To our knowledge, intestinal changes in response to induced colitis have not been examined by bowel ultrasound in animal models. We hypothesize that ultrasound scanning in experimental colitis models can improve our understanding of pathophysiological mechanisms, with particular reference to inflammation.

In the present pilot study, we wanted to investigate (1) whether transabdominal bowel ultrasound using a clinical scanner could demonstrate inflammation in two well-known experimental rat colitis models, and (2) for which model ultrasound imaging was suitable. For this purpose, the rats were exposed to either DSS or TNBS to induce colitis.

\section{Materials and methods Animals}

Sixteen adult male Wistar rats (Møllegaard and Bomholtgaard, Ry, Denmark), with a mean weight of $303 \pm 1.5 \mathrm{~g}$ were housed singly in Makrolon III cages. Access to standard diet, BeeKay rodent low-protein diet consisting of cereal products $(88.5 \%)$, soy protein $(6 \%)$, animal proteins $(2.5 \%)$, soy oil $(0.5 \%)$ and vitamin, mineral, and amino acid supplementation $(2.5 \%)$ (B\&K Universal, Nittedal, Norway) was ad libitum, as was tap water if not otherwise stated. Animals were maintained at a controlled temperature $\left(21^{\circ} \mathrm{C} \pm 1^{\circ} \mathrm{C}\right)$ with a 12-hour light and 12-hour dark cycle (lights on at 0700 ), relative humidity $55 \% \pm 5 \%$ and 20 air changes per hour.

The protocol and the procedures were approved by the Norwegian Animal Research Authority (project number 2009 1908).

\section{Experimental design}

Following 7 days (days 1-7) of acclimatization after arrival, the 16 animals were randomly divided into two groups of eight: group 1 (DSS) and group 2 (TNBS). Table 1 shows a summarized design of the study. Colitis was induced by $5 \%$ DSS in distilled drinking water in group 1 and by a single intracolonic TNBS dosing in group 2. Using transabdominal bowel ultrasound, the wall thickness of the distal colon, cecum, and small bowel were recorded at baseline and 7 days after DSS administration in group 1 and at baseline, and 2 and 7 days later after the TNBS administration in group 2 .

Table I Design of the experimental study

\begin{tabular}{|c|c|c|}
\hline & Group I (DSS) & Group 2 (TNBS) \\
\hline \multicolumn{3}{|l|}{ Day I } \\
\hline \multicolumn{3}{|l|}{ Day 2} \\
\hline \multicolumn{3}{|l|}{ Day 3} \\
\hline Day 4 & Acclimatization & Acclimatization \\
\hline Day 5 & 7 days & 7 days \\
\hline \multicolumn{3}{|l|}{ Day 6} \\
\hline \multicolumn{3}{|l|}{ Day 7} \\
\hline Day 8 & $\begin{array}{l}\text { Ultrasound + blood } \\
\text { and fecal samples }\end{array}$ & \\
\hline Day 9 & & $\begin{array}{l}\text { Ultrasound }+ \text { blood and } \\
\text { fecal samples }\end{array}$ \\
\hline Day 10 & & $\begin{array}{l}\text { Single dose of TNBS } \\
\text { administered }\end{array}$ \\
\hline \multicolumn{3}{|l|}{ Day II } \\
\hline Day 12 & DSS for 7 days & $\begin{array}{l}\text { Ultrasound after } 48 \text { hours }+ \\
\text { blood and fecal samples }\end{array}$ \\
\hline \multicolumn{3}{|l|}{ Day 13} \\
\hline \multicolumn{3}{|l|}{ Day 14} \\
\hline \multicolumn{3}{|l|}{ Day 15} \\
\hline Day 16 & $\begin{array}{l}\text { Ultrasound + blood } \\
\text { and fecal samples }\end{array}$ & \\
\hline Day 17 & Killed + histology & $\begin{array}{l}\text { Ultrasound after I week + } \\
\text { blood and fecal samples }\end{array}$ \\
\hline Day 18 & & Killed + histology \\
\hline
\end{tabular}

Abbreviations: DSS, dextran sodium sulfate; TNBS, trinitrobenzene sulfonic acid. 
Blood and fecal samples were taken from each group on the same days as ultrasonography was performed. Rats were killed by $\mathrm{CO}_{2}$ the day after the final ultrasound examination, and the samples for histology were taken.

\section{Induction of colitis}

In group 1, colitis was induced by $50 \mathrm{~g} / \mathrm{L}$ of DSS (MW 44,000; TdB Consultancy AB, Uppsala, Sweden) given in distilled drinking water for 7 successive days. The solution was refreshed daily, and consumption was measured accordingly. In group 2, rats were restricted from food 24 hours prior to TNBS dosing, and a single dose of TNBS (Sigma-Aldrich Logistik, Heidenheim, Germany) in 50\% ethanol solution $(0.5 \mathrm{~mL} / \mathrm{rat})$ was administered intracolonically by a rectal probe under anesthesia (isofluran). The probe was of polyethylene material, $10 \mathrm{~cm}$ long with $2 \mathrm{~mm}$ external diameter and a balled tip. After the TNBS administration, the probe was gently removed, and the animal remained prone with hind legs raised for at least 30 seconds to minimize leakage. The whole procedure took less than 5 minutes. The animals were monitored until recovery and then transported back to the animal facilities.

\section{Ultrasound examination}

Ultrasound images were obtained using a commercial ultrasound scanner (GE Logiq 9; GE Healthcare, Milwaukee, WI) with a broadband linear array transducer set to $14 \mathrm{MHz}$ (12 L GE Healthcare, MI). Before ultrasound measurements, animals were anesthetized by isofluran, and then placed on a heated platform in a supine position with the abdomen exposed to the transducer. The abdomen was shaved before imaging, and ultrasound gel was gently applied to obtain better contact between skin and transducer. First, symphysis pubis was localized in a longitudinal section of the transducer, and then distal colon was visualized in a standardized view in which the urinary bladder served as a landmark. Thereafter, the transducer was moved to the left upper quadrant to visualize the cecum and to the small bowel in the right upper quadrant. The wall thickness was measured from the start of the hypoechoic layer, corresponding to the proper muscle to the interface echo between the mucosa and lumen. The hyperechoic echo corresponding to the submucosa could not always be identified. In each location, a mean of three measurements was used for further analysis.

\section{Blood and fecal samples}

For analyzing tumor necrosis factor-alpha (TNF- $\alpha$ ), blood was drawn from the saphenous vein during the ultrasound scanning into a heparin-containing Vacutainer, placed on ice for 10 minutes. Phycoerythrin-conjugated hamster anti-rat/ mouse TNF (Becton Dickinson Biosciences, San Jose, CA) was added to $50 \mu \mathrm{L}$ blood and incubated for 30 minutes at $4^{\circ} \mathrm{C}$. A further $1 \mathrm{~mL}$ Becton Dickinson Pharm Lyse lysing buffer was added, and samples were incubated for another 8 minutes at room temperature. Washing was performed twice with $2 \mathrm{~mL}$ phosphate-buffered saline containing $0.5 \%$ bovine serum albumin. Samples were centrifugated at $350 \mathrm{~g}$ for 5 minutes between each washing. TNF-labeled cells were analyzed by FACSCalibur (Becton Dickinson Immunocytometry Systems). Flowjo software version 8.8.6 (Tree Star, Ashland, OR) was used to analyze flow cytometry data, and TNF- $\alpha$ was expressed as median fluorescence intensity.

Fecal samples were obtained to evaluate occult bleeding (HemoFEC; Med-Kjemi, Asker, Norway) in response to induction of colitis (score 0 indicated test negative and 1 test positive).

\section{Tissue preparation and histological assessment}

After ultrasound imaging (days 17 and 18), animals were killed with inhaled $\mathrm{CO}_{2}$, and colon and small bowel were removed for histological examination. The distal part of the small bowel and colon were rinsed with phosphatebuffered saline buffer, opened longitudinally, and colon divided into one proximal (cecum) and one distal segment, which were fixed in 10\% formalin and embedded in paraffin. Eight pieces per segment were stained with hematoxylin and eosin.

Crypt and inflammation scores in colon and small bowel were determined according to a validated scoring system. ${ }^{17}$ The final crypt and inflammation scores are the averages of all individual scores of 16 pieces per colon. Thereafter, combined histology score was used, being the sum of the averages of crypt and inflammation scores.

\section{Statistical analysis}

Data were analyzed using the GraphPad Prism version 5 (GraphPad Software, San Diego, CA) statistical software package. Results are presented as mean \pm standard error of mean. Differences between groups were evaluated using one-way analysis of variance and paired $t$-tests. Correlation between ultrasound measurements and combined histology scores was analyzed using Pearson's correlation test. $P$-values less then 0.05 were considered statistically significant. 


\section{Results}

\section{Ultrasound images}

Compared with baseline values $(0.5 \pm 0.02 \mathrm{~mm})$, the wall thickness of distal colon, but not cecum or small bowel, increased significantly after 7 days of DSS intake in group 1 $(0.9 \pm 0.07 \mathrm{~mm}, P<0.01)$. In group 2 , the wall thickness of both distal colon (baseline, $0.5 \pm 0.03 \mathrm{~mm}$ ) and small bowel (baseline, $0.4 \pm 0.03 \mathrm{~mm}$ ) increased significantly after 2 days (distal colon, $1.2 \pm 0.08 \mathrm{~mm}$; small bowel, $0.7 \pm 0.06 \mathrm{~mm}$; $P<0.05$ ) and 7 days (distal colon, $0.9 \pm 0.1 \mathrm{~mm}$; small bowel, $0.5 \pm 0.03 \mathrm{~mm} ; P<0.05$ ), but the highest thickness increases were recorded 2 days later, after TNBS administration (Figure 1). An ultrasonographic view of the distal colon before and after DSS intake is demonstrated in Figure 2.

\section{Blood and fecal samples}

TNF- $\alpha$ increased significantly after 7 days in group 2, analyzed by median fluorescence intensity (baseline, $2.0 \pm 0.2$; after 7 days, $3.2 \pm 0.2 ; P<0.002$ ). However, no statistical difference was seen in group 1 . In accordance with sonographic features, occult bleeding in fecal samples was positive in five of eight rats after 7 days' DSS intake, and positive in seven of eight rats after 2 days and one of eight rats after 7 days in the TNBS group.

\section{Histology of the colon}

Histological findings in the DSS and TNBS groups were compared with our previous control group, ${ }^{18}$ as the animals were all adult male Wistar rats from the same farm that had gone through the same diet and acclimatization procedure. Microscopic evaluation showed indications of colitis in all rats receiving DSS or TNBS. Changes were most prominent in the distal colon, with areas of erosions, crypt distortion, and inflammatory infiltration (Figure 3). Compared with the control group, combined histology scores of distal colon and small bowel were significantly higher in the DSS and TNBS groups, and cecum in the DSS group. The highest scores were observed in distal colon in the DSS group, and the scores of all segments were generally higher in the DSS group than the TNBS group (Figure 4).

\section{Relationship between histology and ultrasound features}

There was a significant correlation between ultrasonographic measurements and combined histology score of distal colon in the DSS group $(r=0.71, P=0.04)$ (Figure 5). Furthermore, in accordance with sonographic and histologic features, occult bleeding was also positive in both DSS and TNBS groups ( $62.5 \%$ and $87.5 \%$, respectively), hence hemoFEC, histology, and ultrasound findings of distal colon in the DSS group supported one another (Table 2).

\section{Discussion}

To our knowledge, this is the first reported study where transabdominal bowel ultrasound using a clinical scanner was combined with two different experimental colitis models to evaluate intestinal inflammation. We demonstrated increased wall thickness of the distal colon after 1 week DSS administration, and wall thickening of the small bowel and distal colon after single intracolonic TNBS administration ( 2 and 7 days later). Hence both colitis models were suitable to obtain ultrasound images and to show wall thickening in response to inflammation. Interestingly, a significant correlation between ultrasonographic measurements and combined histology score of distal colon was shown in the DSS-group, and positive scores for occult fecal blood also
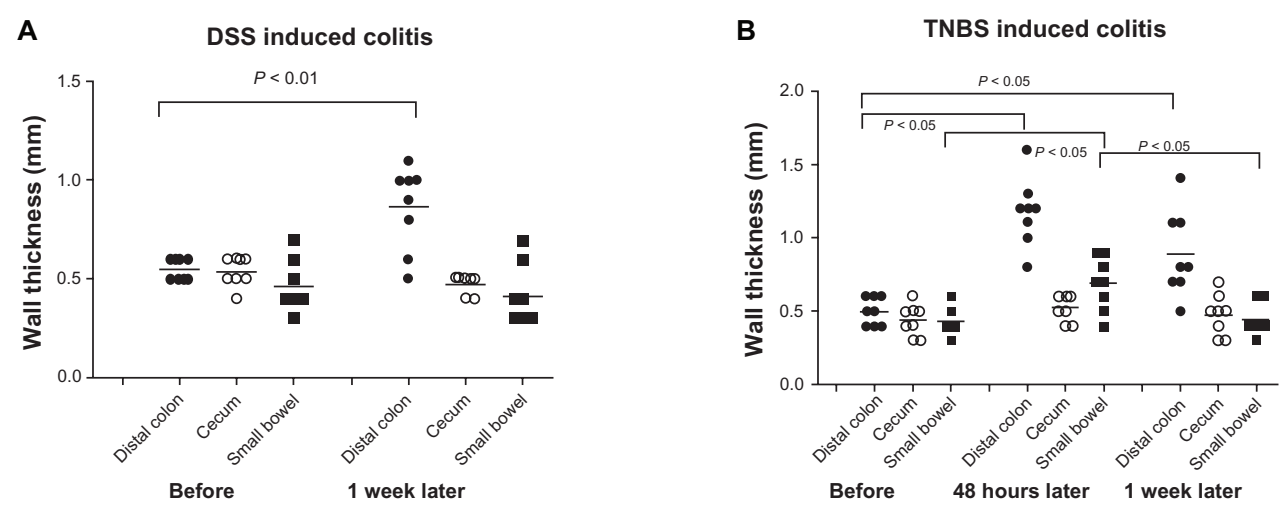

Figure I Changes in the wall thickness of distal colon, cecum and small bowel in rats after 7 days of DSS intake (A) and after a single intracolonic TNBS dosing, measurements 2 and 7 days later (B).

Abbreviations: DSS, dextran sodium sulfate; TNBS, trinitrobenzene sulfonic acid. 

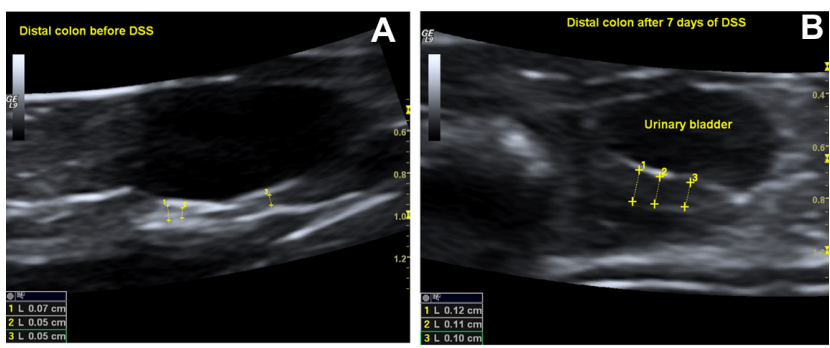

Figure 2 A sonographic view of the distal colon in rat showing distal colon before dextran sodium sulfate (DSS) intake (A) and wall thickening after 7 days of DSS intake (B).

supported inflammation. Accordingly, our study suggests that this particular ultrasonography technique can be applied to evaluate inflammation in rat experimental models of colitis.

IBD is associated with morphological changes of the bowel wall that can be visualized with transabdominal bowel ultrasound. ${ }^{8,19}$ This method is a useful tool for detecting the extent of bowel wall thickening, the length of involved segments and follow-up of the inflammatory process. ${ }^{20,21}$ Compared with other advanced imaging and visualization modalities, such as computerized tomography, magnetic resonance imaging, capsule endoscopy and double-balloon endoscopy, ultrasonography has the advantage of being cheap,
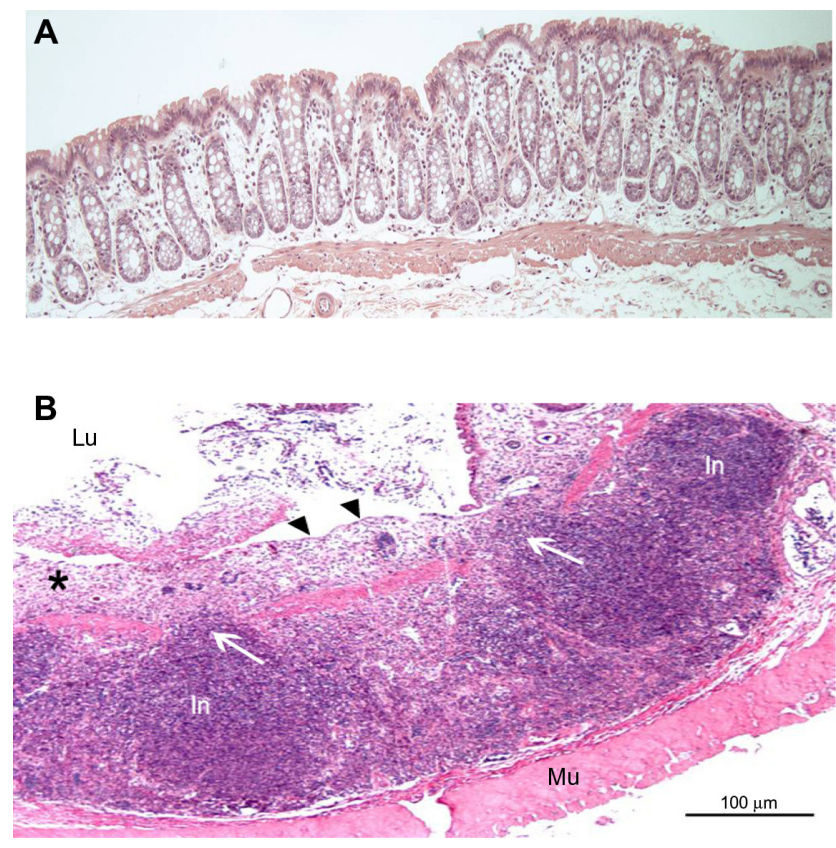

Figure 3 (A) Histologic appearance of the normal colonic mucosa of healthy control rat (intact crypts); (B) distal colon mucosa of rat with dextran sodium sulfate (DSS) colitis (rat no DSS-4) showing inflammatory infiltration and loss of mucosal architecture (see asterisk).

Notes: White arrows, penetration of infiltrations into the connective tissue; black arrows, complete absence of crypts and surface epithelium (hematoxylin and eosin, $\times 10$ ).

Abbreviations: Lu, lumen; In, infiltration; Mu, muscularis. noninvasive, portable, widely available, and patient-friendly. Furthermore, ultrasonography rapidly provides the clinician with image data of high temporal and spatial resolution. However, intestinal air and obesity may impair image quality. The typical ultrasound findings in IBD can be divided into bowel wall changes, focal reactions, and complications of the disease. The wall changes consist of wall thickening, ulcerations, infiltrations, flow alterations, and changes in stratification and perfusion. ${ }^{22-24}$ Importantly, focal reactions such as enlarged lymph nodes around the bowel loops and complications of IBD (fistulas, abscesses, and stenosis with signs of obstruction) can also be visualized using bowel ultrasound. Accordingly, noninvasive quantification of colonic inflammation by bowel ultrasound could advantageously guide dosing regimens, assess drug efficacy, and promote local drug delivery. ${ }^{25}$ Thus it may enhance the value of experimental colitis models in animal research.

Rodents have been widely used to investigate different factors in IBD, including pathophysiological mechanisms and drug activity. Transgenic and mutant strains of mice with specific deficits or inducible colitis models, mainly with DSS or immunological haptens such as TNBS, have been reported. ${ }^{26,27}$ In the TNBS model, a mucosal barrier breaker (ethanol) is administered rectally with the hapten, resulting in an acute injury phase to a longer-lasting immunological phase. ${ }^{27}$ Such chemically induced models of colitis have received much attention because they are simple to induce and evoke widespread immunoinflammatory sequelae in the colon. ${ }^{28}$ Mucosal and submucosal infiltration by leukocytes, macrophages, lymphocytes, and mast cells, including ulceration, fibrosis, and incomplete bowel obstruction, has been shown in this model. ${ }^{29}$

Recently, Shi and colleagues demonstrated that the inflammatory response to DSS was primarily due to oxidative stress, whereas in TNBS colitis the inflammation was due to both oxidative stress and proinflammatory cytokines. ${ }^{30}$ DSS inflammation induced oxidative stress initially in mucosa/ submucosa, which then propagated to the proper muscle layer to impair smooth muscle function. However, TNBS inflammation simultaneously induced oxidative stress, recruited or activated immune cells, and generated cytokines/chemokines in both mucosa/submucosa and the proper muscle layer. Hence impaired smooth muscle function contributed to diarrhoea. ${ }^{30,31} \mathrm{In}$ DSS inflammation, the increase of oxidative stress in the proper muscle layer occurred in the absence of any activated immune cells, and the concentrations of cytokines/chemokines in the mucosa/submucosa in this type of inflammation were smaller than those in Crohn's disease-like inflammation. In contrast to the propagation of oxidative stress in the gastrointestinal 
A

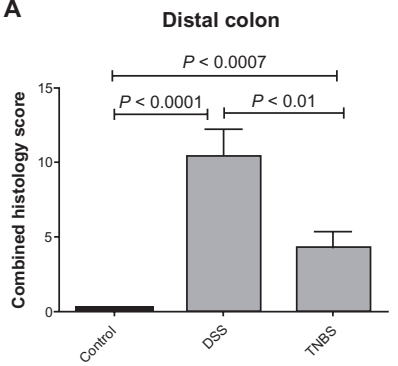

B

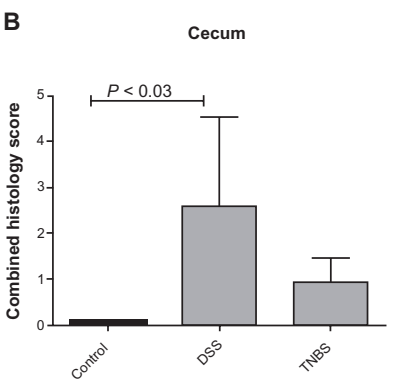

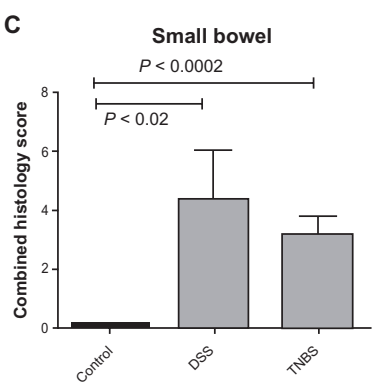

Figure 4 Comparison of combined histology scores of distal colon (A), cecum (B) and small bowel (C) in the dextran sodium sulfate (DSS), trinitrobenzene sulfonic acid (TNBS), and control groups (error bars indicate standard error of mean).

wall over a period of 5-7 days in DSS inflammation, the oxidative stress and cytokine/chemokine concentrations increased almost concurrently in TNBS inflammation. ${ }^{30}$ However, all these studies have only performed in vitro analyses of bowel segments to assess the degree of intestinal damage. In accordance with Shi et al, increased serum TNF- $\alpha$ concentration was also found in our TNBS group after 7 days, but not in DSS inflammation, supporting the role of cytokines also in TNBS-induced colitis.

The present feasibility study has some limitations that need to be addressed. Although a 14-MHz transducer was used in this study, an ultrasound transducer dedicated for small animal scanning with higher frequency $(25-50 \mathrm{MHz})$ and thus better resolution would most likely improve imaging of cecum and small bowel. The best theoretical axial resolution of a 14-MHz probe is only $0.055 \mathrm{~mm}$, while it is $0.019 \mathrm{~mm}$ in a $40-\mathrm{MHz}$ probe. The improved resolution will make it easier to separate structures and should enable the distinction of different wall layers in the rodent gastrointestinal tract. Also,

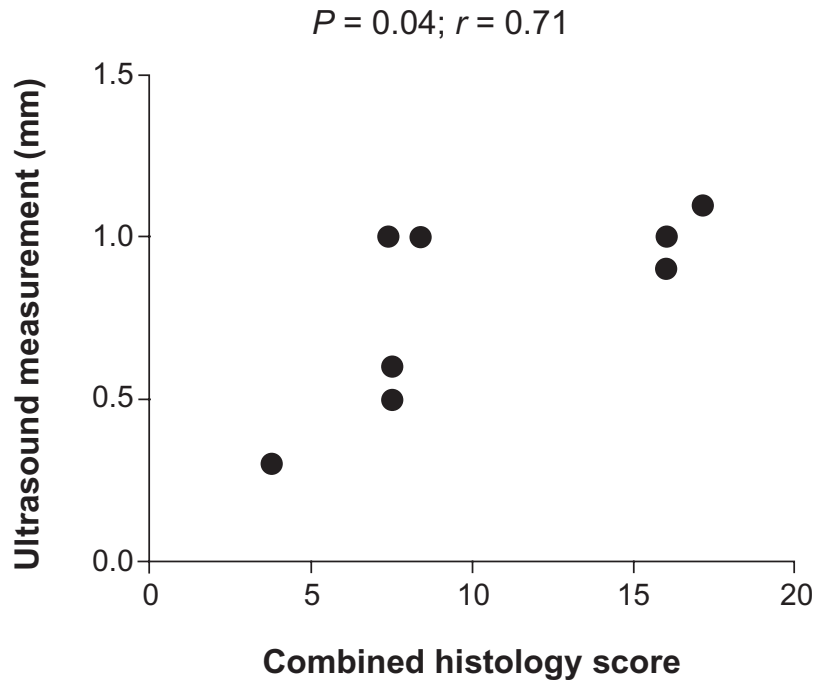

Figure 5 Correlation between ultrasound measurements and combined histological score of distal colon in the dextran sodium sulfate group $(P=0.04, r=0.71)$. an extra TNBS group killed after 2 days should be added to compare histological findings after 2 and 7 days in response to single TNBS dosing. Compared to the DSS group, we found generally less inflammation in all segments of the TNBS group after 7 days and hemoFEC became negative in six of seven rats, showing that a rapid regeneration after the inflammatory response may already have started after 2 days. Therefore, histology should be evaluated in a separate TNBS group after 2 days, when the wall thickness was largest. However, in spite of these limitations, the findings in this pilot study show that we were able to distinguish diseased bowel using a human scanner, and both DSS and TNBS colitis models were suitable for ultrasound imaging.

In conclusion, increased intestinal wall thickness in response to DSS- or TNBS-induced colitis was able to be visualized by transabdominal bowel ultrasound in rats using a clinical scanner. TNF- $\alpha$ increased significantly in the TNBS group but not in the DSS group, supporting the notion that proinflammatory cytokines are involved in the inflammatory process in TNBS-induced colitis models. In the DSS group, ultrasound measurements significantly correlated with the combined histological score in distal colon, and ultrasound, occult blood samples, and histology findings supported one another. Further studies with larger cohorts including the

Table 2 Ultrasound measurements, occult bleeding (hemoFEC), and combined histology scores of distal colon in the dextran sodium sulfate group

\begin{tabular}{llll}
\hline Rat no & Ultrasound $(\mathbf{m m})$ & Hemofec $^{\mathbf{a}}$ & Histology score \\
\hline DSS-I & 0.6 & 0 & 7.5 \\
DSS-2 & 0.5 & $\mathrm{I}$ & 7.5 \\
DSS-3 & $\mathrm{I}$ & $\mathrm{I}$ & 16 \\
DSS-4 & $\mathrm{I} . \mathrm{I}$ & $\mathrm{I}$ & 17.13 \\
DSS-5 & $\mathrm{I}$ & $\mathrm{I}$ & 7.38 \\
DSS-6 & $\mathrm{I}$ & 0 & 8.38 \\
DSS-7 & 0.3 & 0 & 3.75 \\
DSS-8 & 0.9 & $\mathrm{I}$ & 16 \\
\hline
\end{tabular}

Notes: ${ }^{20}$, negative; I, positive. 
use of a higher-frequency transducer for small animals are warranted to establish the exact role of transabdominal bowel ultrasound in experimental colitis with the use of contrast agents also. Moreover, ultrasonography may provide unique and objective monitoring of inflammation, with the great advantage of avoiding unnecessary killing of animals to obtain histological evaluation.

\section{Acknowledgment}

This study was supported by MedViz (http://medviz.uib.no/), a research consortium of Haukeland University Hospital, University of Bergen, and Christian Michelsen Research, Bergen, Norway.

\section{Disclosure}

The authors report no conflicts of interest.

\section{References}

1. Danese S, Fiocchi C. Etiopathogenesis of inflammatory bowel diseases. World J Gastroenterol. 2006;12:4807-4812.

2. Gaudio E, Taddei G, Vetuschi A, et al. Dextran sulphate sodium (DSS) colitis in rats. Dig Dis Sci. 1999;44:1458-1475.

3. Venkatraman A, Ramakrishna B, Pulimood AB, Patra S, Murthy S. Increased permeability in dextran sulphate colitis in rats: time course of development and effect of butyrate. Scand J Gastroenterol. 2000;35: 1053-1059.

4. Milde AM, Arslan G, Overmier JB, Berstad A, Murison R. Proactive effect of an acute stressor on chemical sensitization and permeability of the colon in adult rats. Integr Physiol Behav Sci. 2005;40:35-44.

5. Arslan G, Erichsen K, Milde AM, et al. No protection against DSSinduced colitis by short-term pretreatment with $n-3$ polyunsaturated fatty acids in rats. Integr Med Insights. 2007;2:25-34.

6. Elson CO, Sartor RB, Tennyson GS, Riddell RH. Experimental models of inflammatory bowel disease. Gastroenterology. 1995;109: 1344-1367.

7. Milde AM, Murison R. A study of the effects of restraint stress on colitis induced by dextran sulphate sodium in singly housed rats. Integ $r$ Physiol Behav Sci. 2002;37:140-150.

8. Nylund K, Hausken T, Gilja OH. Ultrasound and inflammatory bowel disease. Ultrasound Q. 2010;26:3-15.

9. Maconi G, Ardizzone S, Parente F, Bianchi Porro G. Ultrasonography in the evaluation of extension, activity, and follow-up of ulcerative colitis. Scand J Gastroenterol. 1999;34:1103-1107.

10. Kimmey MB, Wang KY, Haggitt RC, Mack LA, Silverstein FE. Diagnosis of inflammatory bowel disease with ultrasound. An in vitro study. Invest Radiol. 1990;25:1085-1090.

11. Kunihiro K, Hata J, Haruma K, Manabe N, Tanaka S, Chayama K. Sonographic detection of longitudinal ulcers in Crohn disease. Scand J Gastroenterol. 2004;39:322-326.
12. Parente F, Maconi G, Bollani S, et al. Bowel ultrasound in assessment of Crohn's disease and detection of related small bowel strictures: a prospective comparative study versus $\mathrm{x}$ ray and intraoperative findings. Gut. 2002;50:490-495.

13. Maconi G, Bollani S, Bianchi PG. Ultrasonographic detection of intestinal complications in Crohn's disease. Dig Dis Sci. 1996;41:1643-1648.

14. Soldan M, Schanaider A, Madi K, Zaltman C, Machado JC. In vitro ultrasound biomicroscopic imaging of colitis in rats. JUltrasound Med. 2009;28:463-469.

15. Stidham RW, Xu J, Johnson LA, et al. Ultrasound elasticity imaging for detecting intestinal fibrosis and inflammation in rats and humans with Crohn's disease. Gastroenterology. 2011;141:819-826.

16. Larsson AE, Melgar S, Rehnström E, et al. Magnetic resonance imaging of experimental mouse colitis and association with inflammatory activity. Inflamm Bowel Dis. 2006;12(6):478-485.

17. Carrier J, Aghdassi E, Platt I, Cullen J, Allard JP. Effect of oral iron supplementation on oxidative stress and colonic inflammation in rats with induced colitis. Aliment Pharmacol Ther. 2001;15:1989-1999.

18. Erichsen K, Milde AM, Arslan G, et al. Low dose oral ferrous fumarate aggravated intestinal inflammation in rats with DSS-induced colitis. Inflamm Bowel Dis. 2005;11:744-748.

19. Fraquelli M, Colli A, Casazza G, et al. Role of US in detection of Crohn disease: meta-analysis. Radiology. 2005;236:95-101.

20. Antonelli E, Giuliano V, Casella G, et al. Ultrasonographic assessment of colonic wall in moderate-severe ulcerative colitis: comparison with endoscopic findings. Dig Liver Dis. 2011;43(9):703-706.

21. Goetz M, Neurath MF. Imaging techniques in inflammatory bowel disease: recent trends, questions and answers. Gastroenterol Clin Biol. 2009;33:174-182.

22. Nylund K, Leh S, Immervoll H, Matre K, Skarstein A, Hausken T. Crohn's disease: comparison of in vitro ultrasonographic images and histology. Scand J Gastroenterol. 2008;43:719-726.

23. Nylund K, Ødegaard S, Hausken T, et al. Sonography of the small intestine. World J Gastroenterol. 2009;15:1319-1330.

24. Postema M, Gilja OH. Contrast-enhanced and targeted ultrasound. World J Gastroenterol. 2011;17:28-41.

25. Postema M, Gilja OH. Ultrasound-directed drug delivery. Curr Pharm Biotechnol. 2007;8:355-361.

26. Jurjus AR, Khoury NN, Reimund JM. Animal models of inflammatory bowel disease. J Pharmacol Toxicol Methods. 2004;50:81-92.

27. Pohlmann A, Tilling LC, Robinson A, et al. Progression and variability of TNBS colitis-associated inflammation in rats assessed by contrastenhanced and T2-weighted MRI. Inflamm Bowel Dis. 2009;15: $534-545$.

28. Wirtz S, Neufert C, Weigmann B, Neurath MF. Chemicallyinduced mouse models of intestinal inflammation. Nat Protoc. 2007;2:541-546.

29. Melgar S, Karlsson A, Michaelsson E. Acute colitis induced by dextran sulphate sodium progresses into chronicity in $\mathrm{C} 57 \mathrm{Bl} / 6$ but not in BALB/c mice: correlation between symptoms and inflammation. $\mathrm{Am}$ J Physiol Gastrointest Liver Physiol. 2005;288:1328-1338.

30. Shi XZ, Winston JH, Sarna SK. Differential immune and genetic responses in rat models of Crohn's colitis and ulcerative colitis. Am J Physiol Gastrointest Liver Physiol. 2011;300:41-51.

31. Vrees MD, Pricolo VE, Potenti FM, Cao W. Abnormal motility in patients with ulcerative colitis: the role of inflammatory cytokines. Arch Surg. 2002;137:436-445.
Clinical and Experimental Gastroenterology

\section{Publish your work in this journal}

Clinical and Experimental Gastroenterology is an international, peerreviewed, open access journal, publishing all aspects of gastroenterology in the clinic and laboratory, including: Pathology, pathophysiology of gastrointestinal disease; Investigation and treatment of gastointestinal disease; Pharmacology of drugs used in the alimentary tract;

\section{Dovepress}

Immunology/genetics/genomics related to gastrointestinal disease. This journal is indexed on CAS. The manuscript management system is completely online and includes a very quick and fair peer-review system. Visit http://www.dovepress.com/testimonials.php to read real quotes from published authors. 